Table 1. Clinical and ultrasound parameters in UCTD-risk-SSc and healthy control groups.

\begin{tabular}{|c|c|c|c|}
\hline & $\begin{array}{l}\text { UCTD-risk-SSc } \\
(n=40)\end{array}$ & $\begin{array}{l}=\text { Healthy controls } \\
(n=40)\end{array}$ & $\mathrm{p}$ value \\
\hline Age, mean (SD) & $51.4(14.9)$ & $49.8(13.9)$ & Ns \\
\hline Female, $\mathrm{n}(\%)$ & $36(90.0)$ & $36(90.0)$ & \\
\hline Raynaud phenomenon, \% & $100.0 \%$ & - & \\
\hline ANAs & 100.0 & - & \\
\hline Anti-centromere, \% & 60.0 & & \\
\hline Anti-Scl70+, \% & 11.5 & & \\
\hline $\begin{array}{l}\text { Scleroderma/non-scleroderma pattern in } \\
\text { capillaroscopy, } \%\end{array}$ & $5.0 / 95.0$ & - & - \\
\hline \multicolumn{4}{|l|}{ Ultrasound parameters } \\
\hline \multicolumn{4}{|l|}{ Dermal thickness (mm) } \\
\hline Dorsal hand right & $0.77(0.32)$ & $0.62(0.12)$ & 0.02 \\
\hline Dorsal hand left & $0.79(0.39)$ & $0.62(9.13)$ & 0.02 \\
\hline Proximal phalanx right & $0.64(0.14)$ & $0.61(0.11)$ & Ns \\
\hline Proximal phalanx left & $0.66(0.16)$ & $0.60(0.09)$ & Ns \\
\hline \multicolumn{4}{|l|}{ SWV values $(\mathrm{m} / \mathrm{s})$} \\
\hline Dorsal hand right & $1.94(0.40)$ & $1.61(0.24)$ & 0.0001 \\
\hline Dorsal hand left & $1.82(0.36)$ & $1.65(0.25)$ & 0.025 \\
\hline Proximal phalanx right & $2.09(0.60)$ & $1.68(0.24)$ & 0.001 \\
\hline Proximal phalanx left & $2.13(0.82)$ & $1.66(0.27)$ & 0.004 \\
\hline
\end{tabular}

Legend: ANA: Antinuclear antibodies; Ns: Non-significant; UCTD: Undifferentiated Connective Tissue Disease; SD: Standard Deviation

Disclosure of Interests: None declared

DOI: 10.1136/annrheumdis-2021-eular.3384

\section{POS0879 CLINICAL FEATURES, PROGNOSTIC FACTORS, AND OUTCOME OF ANTI-MDA5 POSITIVE DERMATOMYOSITIS WITH RAPIDLY PROGRESSIVE INTERSTITIAL LUNG DISEASE: A MULTICENTER STUDY OF 238 PATIENTS}

L. Xu ${ }^{1}$, L. Wang ${ }^{1}$, C. LV ${ }^{1}$, W. Tan ${ }^{1}$ on behalf of Myositis Study Group Jiangsu cohort. ${ }^{1}$ The First Affiliated Hospital of Nanjing Medical University, Department of Rheumatology, Nanjing, China

Background: Anti-melanoma differentiation-associated gene 5 positive dermatomyositis (anti-MDA5 ${ }^{+} \mathrm{DM}$ ) is typically amyopathic and associated with a life-threatening, therapy-resistant, rapidly progressive interstitial lung disease (RP-ILD).

Objectives: The present study aims to characterize the prognostic factors and long-term outcome of MDA5 ${ }^{+} \mathrm{DM}$-associated RP-ILD.

Methods: A multicenter retrospective study was performed across ten tertiary hospitals in China between January 1, 2018 to December 31, 2019.

Results: A total of 238 patients (170 women) with $\mathrm{MDA}^{+} \mathrm{DM}$ enrolled into this retrospective clinical study. The mean age was $53.0 \pm 12.2$ years. The median follow-up duration was $6.3 \pm 12.2$ months. Of those 238 anti-MDA5+ patients, ILD is commonly observed in 213 patients, and RP-ILD occurred in $35.29 \%$ (84/213) of these patients (RP-ILD defined as progressive dyspnea occurs within 1 month after the onset of respiratory symptoms, and chest radiography or pulmonary function test show progressive interstitial abnormalities). The mortality rate of RP-ILD patients within the 6 months was 58.3\% (49/84) in our cohort. Death peaked the first three months after diagnosis, occupying $84.8 \%(39 / 46)$ of died RP-ILD patients. Cox univariate proportional hazard analysis showed that age, gender, disease duration, abnormal laboratory features (LDH, CK, ESR and CRP), anti-Ro52 autoantibody and anti-MDA5 grade were related to the risk of occurrence of RP-ILD in patients with $\mathrm{MDA}^{+} \mathrm{DM}$. The Cox proportional hazards model identified the disease duration [odds ratio (OR) $0.81(95 \% \mathrm{Cl} 0.68,0.96)$, $\mathrm{P}=0.016$ ] as a protective factor, and anti-Ro52 autoantibody [OR $5.82(95 \% \mathrm{Cl}$ $1.72,19.73), P=0.005]$ as independent risk factors for the occurrence of RP-ILD in MDA5 $^{+}$DM patients. The 6-month all-cause mortality rate of RP-ILD patients was $58.3 \%(49 / 84)$.

Conclusion: Combined with anti-Ro52 in Myositis-specific antibodies was associated with the occurrence and long-term mortality in $\mathrm{MDA5}^{+} \mathrm{DM}$-associated RP-ILD patients. The results suggest poor overall survival among patients with $\mathrm{MDA}^{+} \mathrm{DM}$-associated RP-ILD. Survival during the first 6 months is crucial for long-term survival. Early recognition and prompt treatment of this high-risk group of MDA5 $5^{+}$DM -associated RP-ILD patients are therefore important.

Disclosure of Interests: None declared

DOI: 10.1136/annrheumdis-2021-eular.3401

\section{POS0880 TWO-MINUTE WALK TEST AS A SIMPLE AND OBJECTIVE OUTCOME MEASURE IN IDIOPATHIC INFLAMMATORY MYOSITIS}

S. K. Dunga ${ }^{1}$, C. Kavadichanda ${ }^{2}$, V. Negi'. ${ }^{1}$ Jawaharlal Institute of Postgraduate Medical Education and Research, Department of Clinical Immunology,
Puducherry, India; ${ }^{2}$ Jawaharlal Institute of Postgraduate Medical Education and Research, Department of Clinical Immunology, Puducherry, India

Background: Manual muscle testing (MMT) and Functional index 2(FI-2) are the usual methods in assessing disease activity in IIM ${ }^{1}$. Limitations of MMT8 include low sensitivity to change, floor/ceiling effect, and under-representation of certain important muscle groups ${ }^{1}$ while $\mathrm{Fl}-2$ takes a longer time to administer. Several Timed function tests (TFTs) like the 2-minute walk test (2MWT) or 30s raise from a chair test and $30 \mathrm{~s} 1 \mathrm{~kg}$ arm rise test may be better alternatives and less time taking ${ }^{2}$. Data looking at the performance of these tests are limited to small controlled studies.

Objectives: To assess the performance of timed function tests against MMT8 and $\mathrm{Fl}-2$ in assessing muscle strength and endurance at baseline, 3 and 6 months of therapy.

Methods: An observational cohort study, included 41 patients with polymyositis and dermato-myositis attending OPD and IPD service of tertiary centre MMT8, FI-2 and Timed function tests were done at baseline, at 3 months and at 6 months. (Figure 1)

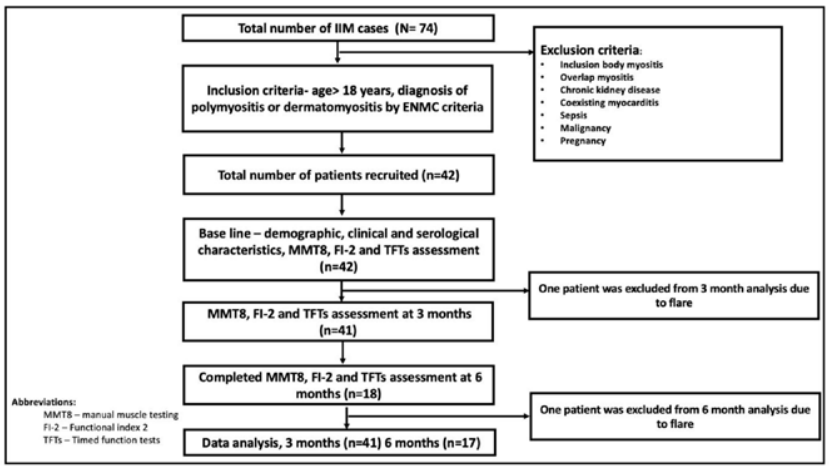

Figure 1. Consort diagram showing the workflow in study population

Results: Forty one patients included in the study had completed three month follow-up assessment, while 17 patients achieved a six-month evaluation. Out of 41 patients, $11(27 \%)$ were polymyositis, and $30(73 \%)$ were dermatomyositis. The mean MMT8 of the total study population at baseline was $57 \pm 15$, at three months $(n=41)$ was $66 \pm 10$ and at six months $(n=17)$ was $71 \pm 10$, while in active subgroup was $50 \pm 18,64 \pm 9(n=41), 67 \pm 9.6(n=17)$ at baseline, three months and six months respectively. The change in TFTs showed a moderate to strong correlation with the change in $\mathrm{Fi}-2$ among the study population at three months and six months (Table 2). Among the TFTs 2MWT showed moderate correlation with both MMT8 and FI-2 in active disease.

Table 1. Spearman Rho Correlation between change in timed function tests with change in MMT8, change in FI-2 at 3 months and 6 months

\begin{tabular}{|c|c|c|c|c|c|}
\hline & & \multicolumn{2}{|c|}{ At 3 months $(n=41)$} & \multicolumn{2}{|c|}{ At 6 months $(n=17)$} \\
\hline & & $\begin{array}{l}\text { Active } \\
\text { disease } \\
(n=18)\end{array}$ & $\begin{array}{l}\text { Inactive } \\
\text { disease } \\
(n=23)\end{array}$ & $\begin{array}{l}\text { Active } \\
\text { disease } \\
(n=7)\end{array}$ & $\begin{array}{l}\text { Inactive } \\
\text { disease } \\
(n=10)\end{array}$ \\
\hline \multirow[t]{3}{*}{ Correlation of $\Delta$ MMT8 with } & $\Delta 30$ s rise form chair & 0.143 & 0.346 & 0.200 & 0.347 \\
\hline & $\Delta 30$ s1 kg arm lift & 0.018 & 0.284 & 0.362 & 0.168 \\
\hline & $\triangle 2 M W D$ & $0.755^{\star}$ & 0.313 & $0.482^{\star}$ & 0.334 \\
\hline \multirow[t]{3}{*}{ Correlation of $\Delta \mathrm{Fl}-2$ with } & $\Delta 30$ s rise form chair & $0.784^{*}$ & $0.495^{*}$ & $0.486^{*}$ & $0.424^{*}$ \\
\hline & $\Delta 30$ s1 kg arm lift & $0.671^{*}$ & 0.107 & $0.704^{\star}$ & 0.301 \\
\hline & $\triangle 2 M W D$ & $0.834^{\star}$ & $0.623^{*}$ & $0.808^{*}$ & $0.506^{\star}$ \\
\hline
\end{tabular}

${ }^{*} \mathrm{p}<0.05$

Conclusion: Using timed function tests can be an excellent alternative to $\mathrm{Fl}-2$ in assessing muscle endurance. 2-minute walk distance is a better alternative to conventional muscle testing as it measures both power and endurance, and this can overcome the ceiling effect of MMT-8.

\section{REFERENCES:}

[1] Rider LG, Aggarwal R, Machado PM, Hogrel J-Y, Reed AM, Christopher-Stine L, et al. Update on outcome assessment in myositis. Nat. Rev. Rheumatol. 2018;14:303-18.

[2] Agarwal S, Kiely PD. Two simple, reliable and valid tests of proximal muscle function, and their application to the management of idiopathic inflammatory myositis. Rheumatology. 2006 Jul 1;45(7):874-9.

Acknowledgements: I would like to acknowledge my patients, my teachers, colleagues, and paraclinical staff of the department of Clinical Immunology JIPMER Disclosure of Interests: None declared

DOI: 10.1136/annrheumdis-2021-eular.3461 